\title{
Soil-structure interaction effects on the seismic performance of frame structures
}

\section{Efecto de la interacción suelo-estructura en el rendimiento sísmico de estructuras de marco}

\author{
Dhahbia Guerdouh \\ Laboratoire de Génie Civil et Environnement (LGCE), Université de Jijel \\ 18000 Jijel (Algeria) \\ dhahbia@hotmail.com
}

Salah Khalfallah (Main and Corresponding author)

Ecole Nationale Polytechnique

B.P 75, A, Nouvelle Ville, 25000 de Constantine (Algeria)

khalfallah_s25@yahoo.com

Manuscript Code: 1311

Date of Acceptance/Reception: 01.08.2019/23.01.2019

DOI: 10.7764/RDLC.18.2.349

\begin{abstract}
In this work, a numerical attempt has been elaborated to study the effects of soil properties, seismic impact and interaction between frame structure and soil foundation. The frame, soil and interface continuum have been modeled by using the finite element concept. In this approach, a numerical program has been established based on the direct method to analyze the soil-structure interaction under seismic loading. Adding, the developed thinlayer interface element ensuring the incompatibility of degrees of freedom between frame and soil elements is incorporated. Obtained results lead to explain (1) the influence of the soil-structure interaction on the seismic response of the frame structure and interface media, (2) the time history deflection of the superstructure and interface medium under seismic loading, (3) the effect of the interaction factor of soil-structure interaction on the seismic behavior of the interface medium and frame structure and (4) the earthquake intensity on the seismic damage. Lateral displacements at the top of the frame and at the interface level, and shear stresses at the contact between the foundation and structure are plotted and commented.

Key words: Soil-structure interaction, seismic excitation, interface element, finite element method, seismic performance, soil properties, direct stiffness method.

\section{Resumen}

En este trabajo, se ha elaborado un intento numérico para estudiar los efectos de las propiedades del suelo, el impacto sísmico y la interacción entre la estructura del marco y los cimientos del suelo. El marco, suelo e interfaz se han modelado utilizando el concepto de elementos finitos. En este enfoque, se ha establecido un programa numérico basado en el método directo para analizar la interacción entre la estructura del suelo y la carga sísmica. Además, se incorpora el elemento de interfaz de capa delgada desarrollado, que garantiza la incompatibilidad de los grados de libertad entre el marco y los elementos del suelo. Los resultados obtenidos conducen a explicar: (1) la influencia de la interacción entre la estructura del suelo y la respuesta sísmica de la estructura del marco y los medios de interfaz, (2) la desviación del historial de tiempo de la superestructura y el medio de interfaz bajo carga sísmica, (3) el efecto del factor de interacción de la interacción entre la estructura del suelo y el comportamiento sísmico del medio de interfaz y la estructura del marco y (4) la intensidad del terremoto en el daño sísmico. Los desplazamientos laterales en la parte superior del marco y en el nivel de la interfaz, y las tensiones de corte en el contacto entre la base y la estructura, se trazan y comentan.
\end{abstract}

Palabras clave: Interacción suelo-estructura, excitación sísmica, elemento de interfaz, método de elementos finitos, rendimiento sísmico, propiedades del suelo, método de rigidez directa.

Most structures such as footings, micro-piles, mat foundations, retaining walls, drilled shafts, etc., are in contact with the soil involving a transfer of loadings. These transferred loads generated at the interface level between the foundation and the soil. Particularly under earthquake loading, this phenomenon is an important task for researchers and engineers because their consequences have significant impacts on the humanity, the social and eco-system of countries (Greer, 2012).

At current state, the soil-structure interaction is one of the most flourishing areas of research in the structural engineering domain. Its effect on the seismic performance of frame structure and the interaction themselves has attracted a special interest of researchers. Most of their activities are focused on the theoretical analysis and numerical approaches, while less has been done on laboratory studies. In the past, this phenomenon is neglected considering that 
the structure is perfectly fixed at its foundation and rarely integrated in the analysis by using empirical approaches. Really, the flexibility of the soil media leads to supplementary deformations under static or dynamic loadings.

During recent years, the soil-structure interaction problem has been taken into consideration mostly in studying the seismic response of structures or infrastructures. Adding, the latest seismic codes and norms recommended the integration of the soil-structure interaction phenomenon in the design phase, which is an important step toward more realistic seismic designs of structures (Millen et al., 2014; Liratzakis \& Tsompanakis, 2018; Gazetas, 2015; Nibhorkar, 2017; Pecker et al., 2014). The task of the interaction must be modeled rigorously in order to describe the interfacial medium contribution in the behavior of the system. Early, this phenomenon was taken into account in a simplified way by assuming the structure fixed at its base (Tabatabaiefar et al., 2010; Teodoru, 2009; Mayer \& Gaul, 2007) but even in most cases, the soil under foundation is flexible and deformable.

The literature regroups two categories of the dynamic soil-structure interaction modeling, (1) the direct method and (2) the substructure method. In the second approach, the analysis is decomposed into different stages applying the superposition principle, which differentiates the main causes of the interaction of the soil structure without the deformation of the free field (Mylonakis et al., 2006; Çelebi et al., 2012; Fu, 2015). While in the direct method, the inertial interaction is taken into account in a single step. In this case, the components: soil, interface and superstructure are modeled together using the finite element method and analyzed in single step (Chinmayi \& Jayalekshmi, 2016; Penava et al., 2018). The ground motion is specified as free field motion and applied at all boundaries. The soil domain is limited by fictitious boundaries, which must be placed so far away from the structure during the seismic excitation, the waves generated along the soil-structure interaction doesn't reach it. The direct method suffers few shortcomings: (1) only a limit zone of the soil may capture the essential aspect of the nonlinear behavior related to soft soil conditions, (2) the well representation of damping is very difficult, (3) the size of 3D-problems becomes very large and the modeling of soil-foundation-interface-structure becomes complex. To overcome this difficulty, various approaches of artificial boundaries have been developed to simplify the SSI analysis, which are regrouped in (1) viscous boundaries method (Lysmer \& Kuhlemeyer, 1969) and (2) infinite elements approach (Zienckiewicz \& Bettess, 1976).

In this domain, various studies have already treated the influence of soil properties and soil-structure interaction on the structural seismic response (Thusoo et al., 2015; Martinez-Rodrigo et al., 2018; Medina et al., 2013). Many works deal with the determination of natural periods of framed buildings due to the effect of soil flexibility. Bhojegowda and Subramanya (2015) have studied frame structures built on isolated, mat and pile foundations for different types of soil like soft, medium and hard strata with regular and irregular buildings. Different soil properties can affect the seismic waves during passing through a soil layer. It means that the movement of the whole ground structure system is influenced by the type of soil. In this way, an attempt has been made to study the soil-structure interaction effect on multi storied buildings with various foundation systems (Elwi et al., 2018). In this study, multi storied buildings with fixed and flexible support subjected to seismic forces were analyzed under different soil conditions like hard, medium and soft.

In this way, buildings resting on soft and very soft soil types are considered and the analysis is done for both fixed and flexible bases (Behnamfar \& Banizadeh, 2016; Ismail, 2014; Adhikary et al., 2015; Tomeo et al., 2017). These studies concluded that soil-structure interaction worsens the performance of structural members of lower stories of moment and shear wall buildings. The effect of the superstructure rigidity on the damping and differential settlement taking into account the redistribution of loads was investigated (Farouk \& Farouk, 2016). In the same way, EN 1998-1 (2004) evaluates the impact of relative stiffness of soil and structure on the dynamic responses. The code states that important structures as: silos, offshore caissons and bridges, tall structures, and structures supported on very soft soils, the soilstructure interaction is recommended to be used in the design.

In this contribution, three aspects have been studied: (1) the influence of soil properties, (2) the effect of seismic impact and (3) the correlation between the soil and frame structure. In this analysis, a new interface finite element already developed is integrated in the numerical program to model the interface medium. In this environment, the frame structure and the soil continuum are modeled using beam and plane strain state elements, respectively. Therefore, the influence of soil properties, the seismic impact and the contribution of the soil-frame interaction are quantified and corresponding results are commented. 


\section{Modeling of the super and sub-structures}

The phenomenon of soil-structure interaction inundated the structural engineering domain by numerous studies. Under static loading, this effect is considered in a simplified way and becomes an evident task in computing phase (Boudaa \& Khalfallah, 2019). These studies lead to clearly the importance of the soil-structure interaction to estimate real forces in structural members. More, the soil-structure interaction should be taken into account in analyzes especially under dynamic or seismic loading to predict the overall structural response (Ferro, 2013). In this case, we can cite the change in natural period of vibrations which may alter the seismic response of any structure. Observations from recent earthquakes have shown that the response of the foundation and the soil can greatly influence the overall structural response (Ramancharla, 2015), (Zafarkhah \& Dehkordi, 2017).

In this subject, the modeling of the soil-structure interaction dynamic is distinguished by the nature of the unbounded soil-structure interaction interface problem (Figure 1). In this study, the direct method is chosen and the equation of motion of the whole system in time domain can be written as:

$$
[M]\{u(t)\}+[C]\{u(t)\}+[K]\{u(t)\}=-[M]\left\{y_{a}(t)\right\}
$$

Where $[M],[C]$ and $[K]$ are $(n \times n)$ the mass, damping and stiffness matrices of the entire system and $n$ is the number of degree of freedom. $\ddot{u}(t), \dot{u}(t)$ and $u(t)$ are the acceleration, velocity and relative displacement vectors of the system nodes and $\ddot{y}_{a}$ is the input ground acceleration vector of the motion (Çelebi et al., 2012; Hokmabadi, 2014).

Figure 1. Representation of the modeling using the direct method. (Self-Elaboration).

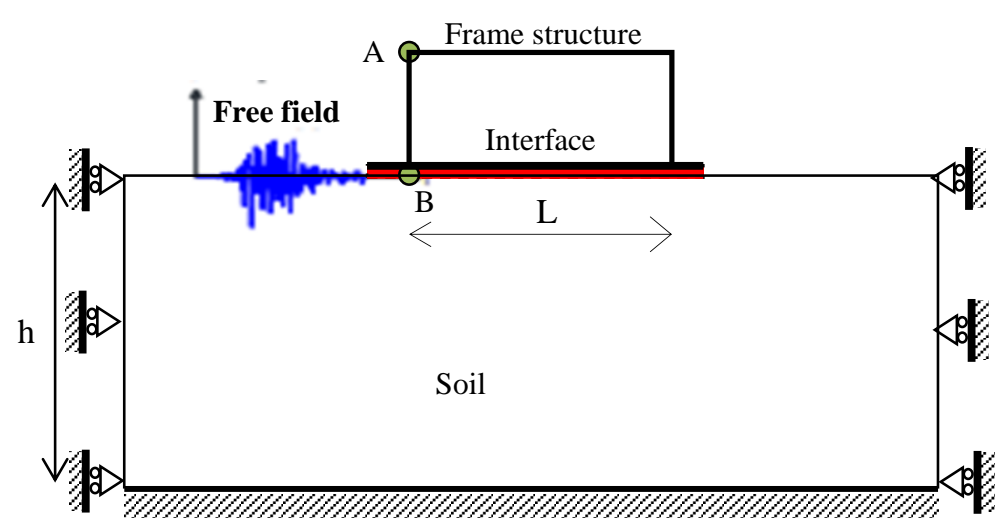

$\mathrm{L}_{\mathrm{s}}$

Each matrix $[\mathrm{K}]$ and $[\mathrm{M}]$ is a combination of that of the frame, interface and soil, as:

$$
\begin{aligned}
& {[K]=\left[K_{b}\right]+\left[K_{i}\right]+\left[K_{s}\right]} \\
& {[M]=\left[M_{b}\right]+\left[M_{i}\right]+\left[M_{s}\right]}
\end{aligned}
$$

The index b, i and s stand for frame (beam), interaction media and the soil, respectively.

Based on the Rayleigh damping concept (Zienkiewicz \& Taylor, 1991), the damping matrix $C$ is computed as a combination of the mass matrix and the stiffness matrix with the enumerated Newmark parameters $\gamma$ and $\beta$ taken into account as:

$[C]=\gamma[M]+\beta[K](4)$ 
The system of coupled equations (1) is represented as finite element model with lumped mass approach. To solve this system of equations, the numerical integration method of Newmark is employed. This numerical method leads to the development of a system composed of time-stepping equations regrouped in the Figure 2 and the resulting responses are obtained at each time step.

Figure 2. Steps of the Newmark method (Source: Hashamdar et al., 2011).

\section{Initial calculation}

Compute stiffness, mass and damping matrices of the entire structure : $\mathrm{K}, \mathrm{M}$ and $\mathrm{C}$ (if used)

Specify the parameters $\beta$ and $\gamma$.

Constant acceleration $\left(\gamma=\frac{1}{2}, \beta=\frac{1}{4}\right)$

Linear acceleration $\left(\gamma=\frac{1}{2}, \beta=\frac{1}{6}\right)$

Select the time step $\Delta t$

Compute constants of integration $b_{1}=\frac{\gamma}{\beta(\Delta t)}, b_{2}=\frac{1}{\beta(\Delta t)^{2}}, b_{3}=\frac{1}{\beta(\Delta t)}, b_{4}=b_{1} \Delta t$

$$
b_{5}=\frac{1}{2 \beta}, \quad b_{6}=\left(\frac{\gamma}{2 \beta}-1\right)(\Delta t)
$$

Effective matrix of stiffness $\bar{K}=K+b_{2} M+b_{4} C$

fompute $\left\{\begin{array}{l}a=b_{3} M+b_{4} C \\ b=b_{5} M+b_{6} C\end{array}\right.$

Specify initial conditions : $u_{0}, \dot{u}_{0}, \ddot{u}_{0}$ with $\ddot{u}_{0}=\frac{F_{0}-C \dot{u}_{0}-K u_{0}}{M}$

\section{Time stepping}

Compute of the effective force vector: $\Delta \bar{F}_{l}=\Delta F_{i}+a \dot{u}_{i}+b \ddot{u}_{i}$

At time $t_{i}$, solve the equation: $\Delta u_{i}=\frac{\Delta \bar{F}_{i}}{\bar{K}}$

Compute the increment of the velocity and the acceleration :

Compute at $(i+1)$ the displacement, velocity and acceleration

$$
\left\{\begin{array}{l}
\Delta \dot{u}_{i}=b_{1} \Delta u_{i}-b_{4} \dot{u}_{i}-b_{6} \ddot{u}_{i} \\
\Delta \ddot{u}_{i}=b_{2} \Delta u_{i}-b_{3} \dot{u}_{i}-b_{5} \ddot{u}_{i}
\end{array}\right.
$$

$$
\begin{aligned}
& u_{i+1}=u_{i}+\Delta u_{i} \\
& \dot{u}_{i+1}=\dot{u}_{i}+\Delta \dot{u}_{i} \\
& \ddot{u}_{i+1}=\ddot{u}_{i}+\Delta \ddot{u}_{i}
\end{aligned}
$$

\section{Obtained results}

- Collect for each time step: $u_{i}, u_{i}, u_{i}$

\section{Numerical modeling}

The solving of the governing equations of motion (Eq. 1) is relatively complex unlike ordinary dynamic time history equations that are a combination of different vectors and matrices of the soil and structure. This combination makes dynamic equations too mathematically sophisticated to be solved by the conventional methods. The direct method is better in modeling the complex nature of the soil-foundation-structure interaction in dynamic analysis. The seismic-soil structure interaction analysis of the proposed two-dimensional finite element model by employing the developed program is executed in the time domain. The finite element program was developed for this concern allowing the simulation of the soil-foundation-structure systems. The numerical procedure of modeling used to simulate structural elements and soil models, as well as the contact surfaces and boundary conditions is explained on the below section.

\section{Soil mass}

The soil foundation is considered as a continuum and discretized to 2D-quadrilateral finite elements having 4 nodes with 2 degrees of freedom (dof) for each node. The soil is assumed to be linear, elastic and isotropic. Due to the geometry conditions, soil-elements are analyzed in plane strain state (Figure 3a). 


\section{Frame elements}

Beams and columns constituting the frame structure are modeled as beam elements with 2 nodes per element and 3 dof at each node; two translations and a rotation. They are conceived to resist axial force, shear effort and bending moment (Figure 3a).

Interface elements

The behavior of the interface media between the soil and foundation is a research of particular importance, it has been found so influenced by the interaction phenomenon. Therefore to idealize the interfacial behavior of soil-framed structure interaction, Shoaei et al. (2015) have developed a new thin-layer interface element to analyze the effect of the soil-structure interaction.

Interface elements are localized into the thin medium between the bottom of the structure and the top of the soil foundation. The thin layer of soil under the foundation is meshed to 2D-quadrilateral finite elements having 4 nodes with 10 dof; 3 dof per node for top nodes while each bottom node has 2 dof, this new thin finite element is developed by authors (Guerdouh \& Khalfallah, 2019). The soil is assumed to be linear, elastic and isotropic (Figure 3a).

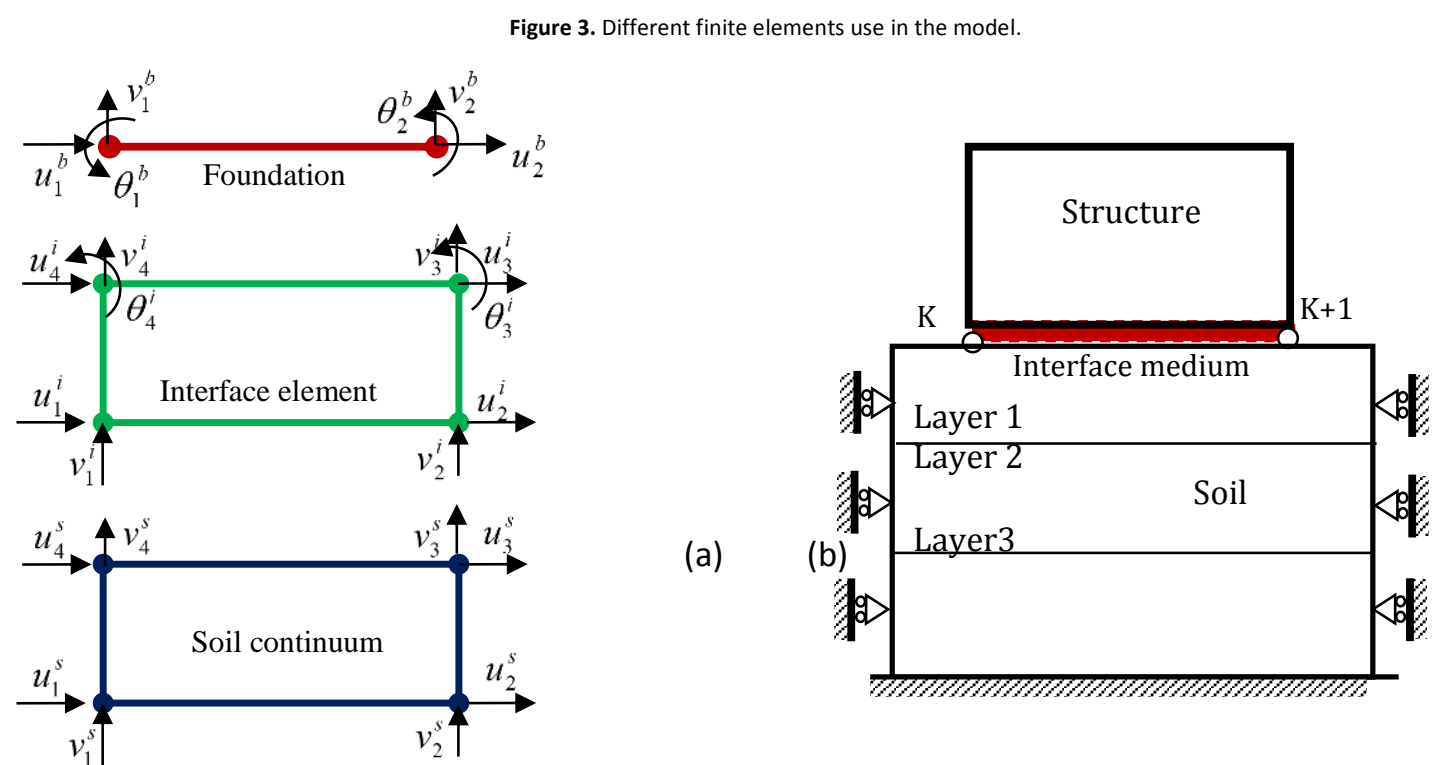

To analyze the frame structure-soil interaction, a parameter describing the relative rigidity of the frame and soil denoted by $\xi$, is defined as:

$\xi=\frac{I_{b}}{I_{s}}(5)$

where $I_{b}=\frac{E I}{L^{3}}$ and $I_{s}=\frac{E_{s} b h^{3}}{12 L_{s}^{3}}$ are the beam and the soil rigidities, respectively.

The flowchart of the developed program (Fig. 4) is based on the common parts constituting every finite element code. Even linear analysis algorithm is constituted of four steps: (1) the data of the problem, (2) the elaboration of the static linear analysis (3) the dynamic elastic analysis and (4) the presentation of obtained results.

More, to show the seismic impact on the frame structure and on the interface medium, a seismic analysis is conducted considering a single layer and thereafter stratified soil layers (Figure3b). Even, seismic record effects are considered applied at the interface level between the frame structure and soil foundation (Figure 1). Load intensity is derived from the seismic scale, which is explained by the Peak Ground Acceleration (PGA) that is in general expressed in g's acceleration. To analyze the impact of earthquakes, three different sets of earthquake ground motion used in this study are summarized in the Table 1 (NIED, 2018). 
Table 1. Earthquake ground motions

\begin{tabular}{cllcc}
\hline PGA $\left(\mathrm{m} / \mathrm{s}^{2}\right)$ & \multicolumn{1}{c}{ Earthquake } & Date & Magnitude & Depth $(\mathrm{Km})$ \\
\hline $2.7 \mathrm{~g}$ & Tohoku earthquake & 2011 & 9 & 30 \\
$1.7 \mathrm{~g}$ & Northridge earthquake & 1994 & 6.7 & 19 \\
$0.8 \mathrm{~g}$ & Kobe earthquake & 1995 & 6.8 & 16 \\
\hline
\end{tabular}

The time history simulations were performed under three historical earthquake excitations with different frequency contents as mentioned in the Table 1.

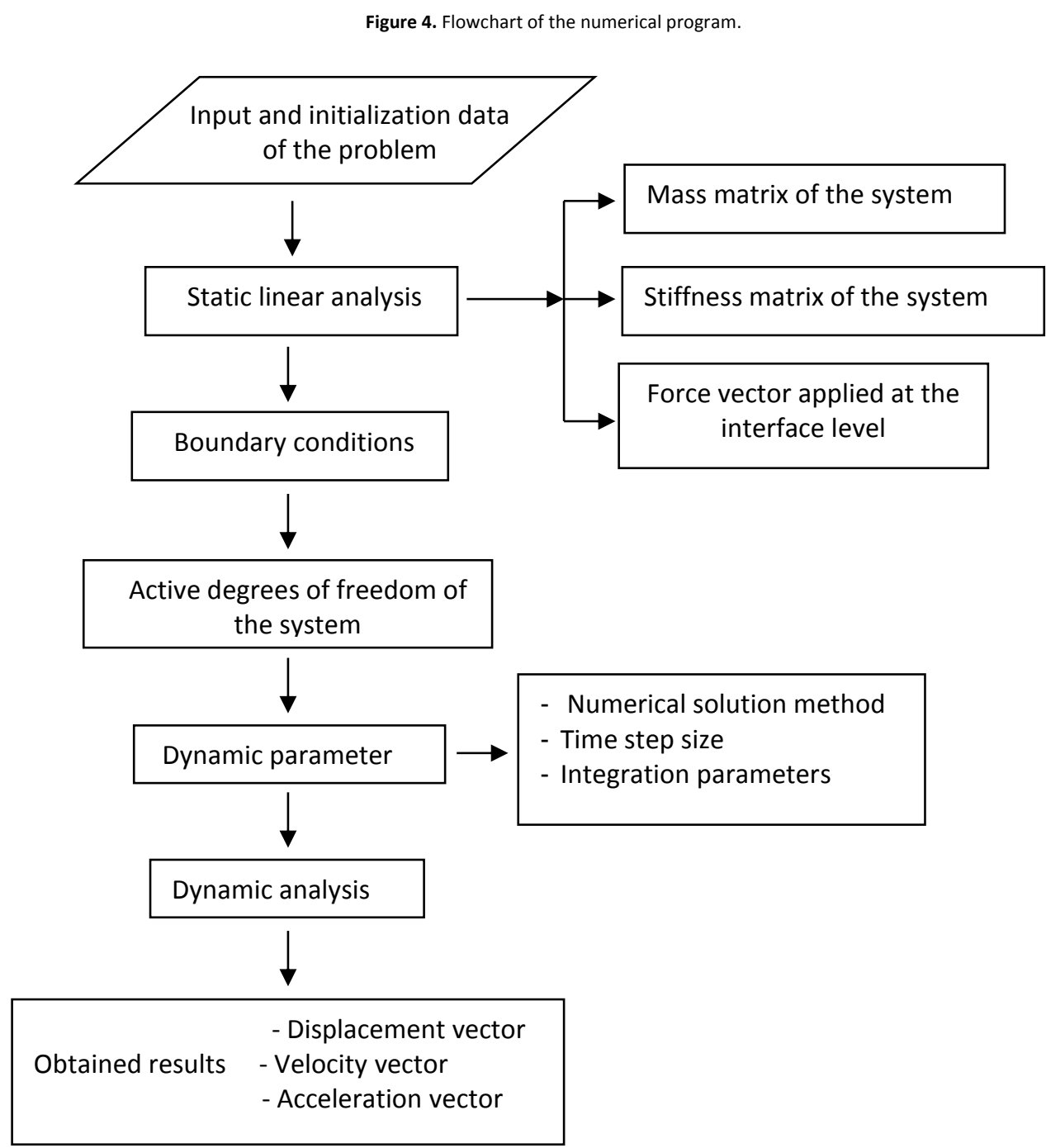

\section{FE modeling for time history analysis}

This section discusses the issues related to the time history analysis of domains using the FEM.

\section{Soil mass}

Using the finite element method, it's possible to model the soil domain of arbitrary geometry and layered profiles. As finite soil domain must inevitably be used, the boundary conditions must be imposed to imitate the infinite of the soil. To improve response of the soil, the boundary conditions must be modeled appropriately. For these reasons, twodimensional soil domain of length $\mathrm{L}_{s}=180 \mathrm{~m}$ and depth $\mathrm{h}=80 \mathrm{~m}$ is considered ensuring to the fictitious boundaries (Figure 1). Both vertical sides are restrained in the horizontal direction while the base is restrained in the horizontal and vertical directions. The frame structure is assumed to be resting on three different homogeneous soils whose constitutive laws are linear elastic. The Table 2 regroups the mechanical and physical properties of the soils used. 
Table 2. Mechanical and physical parameters of soils. Source: Shoaei et al. (2015).

\begin{tabular}{lcccc}
\hline \multicolumn{1}{c}{ Soil of layer } & $\begin{array}{c}\text { Depth } \\
\mathrm{h}(\mathrm{m})\end{array}$ & $\begin{array}{c}\text { Gravity Density } \\
\rho\left(\mathrm{KN} / \mathrm{m}^{3}\right)\end{array}$ & $\begin{array}{c}\text { Poisson } \\
\text { ratio } v\end{array}$ & $\begin{array}{c}\text { Elastic modulus } \\
\mathrm{E}(\mathrm{MPa})\end{array}$ \\
\hline Soft soil & 10 & 18 & 0.40 & 15 \\
Medium soil & 20 & 18 & 0.35 & 30 \\
Hard soil & 50 & 18 & 0.30 & 60 \\
\hline
\end{tabular}

When the soil foundation is stratified, three combinations are selected; Case 1: a soft soil is assumed along the depth, Case 2: a soft layer $(10 \mathrm{~m})$ on a medium layer $(20 \mathrm{~m})$ and Case 3 : soft layer $(50 \mathrm{~m})$, medium layer $(2 \mathrm{~m})$ and a hard layer of $4 \mathrm{~m}$ (Figure 2).

\section{Frame elements}

The geometrical and mechanical properties of the frame elements are regrouped in the Table 3.

\begin{tabular}{ccccccc}
\multicolumn{7}{c}{ Table 3. Mechanical and geometrical characteristics of frame structure. Source: Shoaei et al. (2015). } \\
\hline $\begin{array}{c}\text { Number } \\
\text { of story }\end{array}$ & $\begin{array}{c}\text { Span } \\
\text { width }(\mathrm{m})\end{array}$ & $\begin{array}{c}\text { Height } \\
(\mathrm{m})\end{array}$ & $\begin{array}{c}\text { Cross section } \\
\left(\mathrm{m}^{2}\right)\end{array}$ & $\begin{array}{c}\text { Density } \\
\rho\left(\mathrm{KN} / \mathrm{m}^{3}\right)\end{array}$ & $\begin{array}{c}\text { Poisson } \\
\text { ratio } v\end{array}$ & $\begin{array}{c}\text { Elastic modulus } \\
\mathrm{E}\left(\mathrm{KN} / \mathrm{m}^{2}\right)\end{array}$ \\
\hline 1 & 5 & 3 & $0.4 \times 0.4$ & 2.5 & 0.2 & $3.2^{*} 10^{7}$ \\
\hline
\end{tabular}

\section{Interface media}

As mentioned previously, the soil and the structure are modeled together in a single step. To take into account the behavior of the fine interface between the foundation and soil, anew thin layer finite element is employed to model the interface medium. A 2D quadrilateral finite element having 4 nodes with a combination of degrees of freedom of top and bottom sides guarantying the compatible conditions of displacements between beam elements and soil elements is developed (Guerdouh \& Khalfallah, 2019).

Results and discussion

A transient time history analysis was conducted to study the influence of varying soil properties, seismic impact and interaction between the soil and the frame structure. In this case, two nodes are selected from the frame and interface media. The first point reflects the structural response and the second one devotes to the soil-structure interaction behavior.

\section{Influence of the properties of soil}

To understand different transient behavior of the frame structure and free field responses, three record earthquakes are considered in this study (Figure5): strong earthquake (Tohoku 2011), medium intensity (Northridge 1994) and low intensity (Kobe 1995). In this way, Espinoza et al. (2018) have recently studied the influence of the seismic excitation frequencies on a structure built over different types of soil (soft, medium, hard) considering explicitly of the soil-structure interaction. This study leads to optimize the tuned mass damper of the system considering law and high frequency excitations. 
Figure 5. Acceleration time history of earthquakes used. (a) Tohoku earthquake (2011); (b) Northridge earthquake (1994); (c) Kobe earthquake (1995)
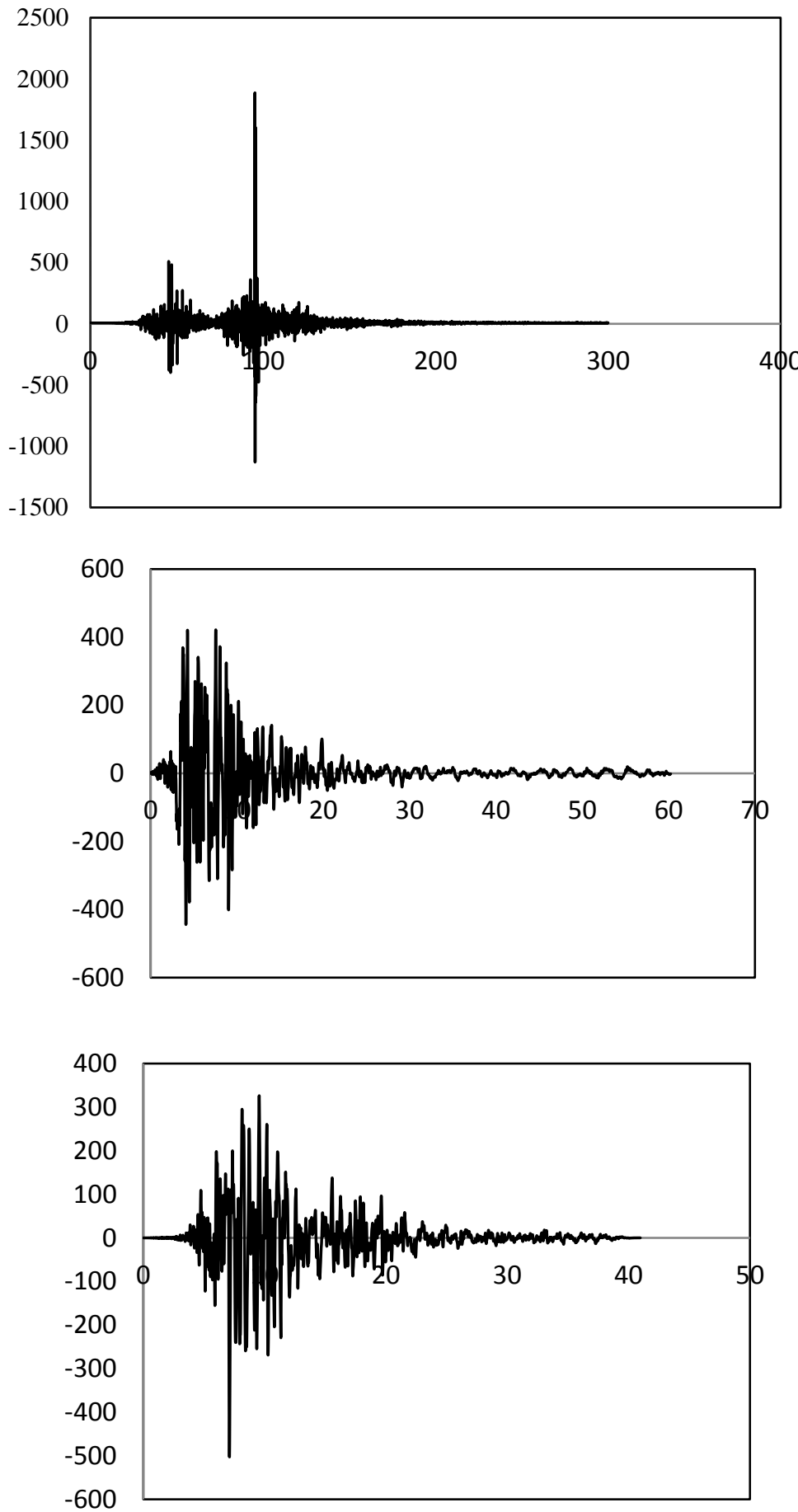

In addition, the acceleration records of earthquakes (Table 1) are implemented in the numerical program and obtained results of this simulation are illustrated in the Figure 5. The dynamic responses are elaborated to calibrate the participation of interface media and soil under foundation into the global system response.

\section{Influence of the soil properties on frame structure}

In order to show the influence of the soil properties on the structural response and interface medium, a seismic analysis is carried out to evaluate the response of frame structure built of different type of soil (Table 3). The results of the analysis including lateral deflection of the frame have been computed for three types of soil, so as to clarify the effect of the subsoil rigidities on the seismic response of frame structure and interface media. 
Figure 6. Influence of soil properties on the frame structure. (Self-Elaboration).
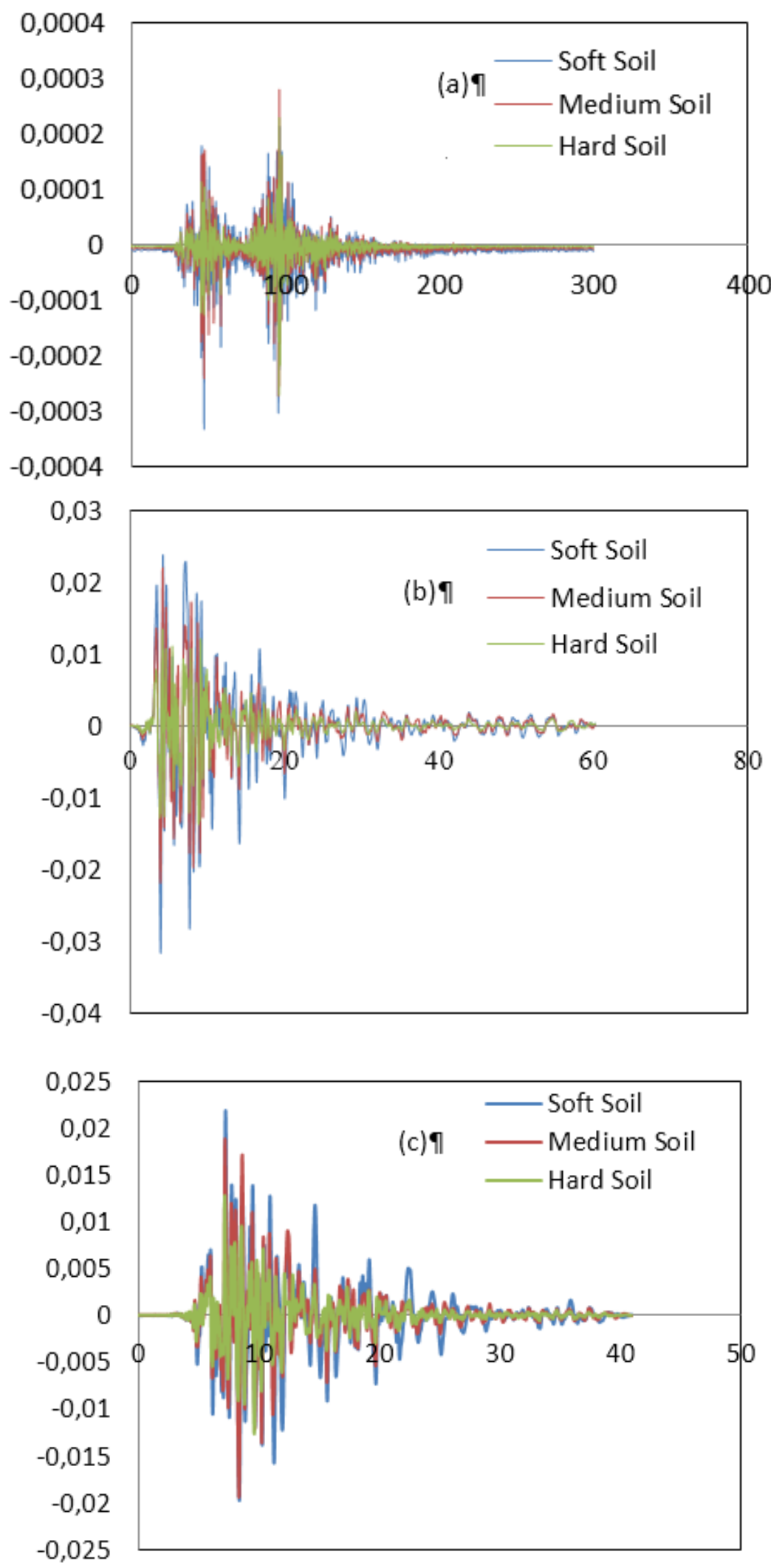

Analyzing obtained results (Figure6), the conclusions can be drawn are:

1- Frame structures subjected to various earthquake loadings behave according to their mechanical characteristics.

2- Due to the importance of inertial and kinematic interaction, the hard soils appear low displacements compared to medium and soft soils. Thus the soil properties have an important effect on the performance of the framed structures under seismic loading. 
3- Adding, the frame structure responds to the earthquake intensity proportionally to the soil mechanical characteristics.

4- The response of the structure is consistent with the histogram of the considered earthquake.

\section{Influence of the soil properties on interfacial medium}

Also, this study is devoted to the assessment of the behavior of the interaction between the soil and frame structure.

Figure 7. Influence of soil properties on the interaction medium. (Self-Elaboration).
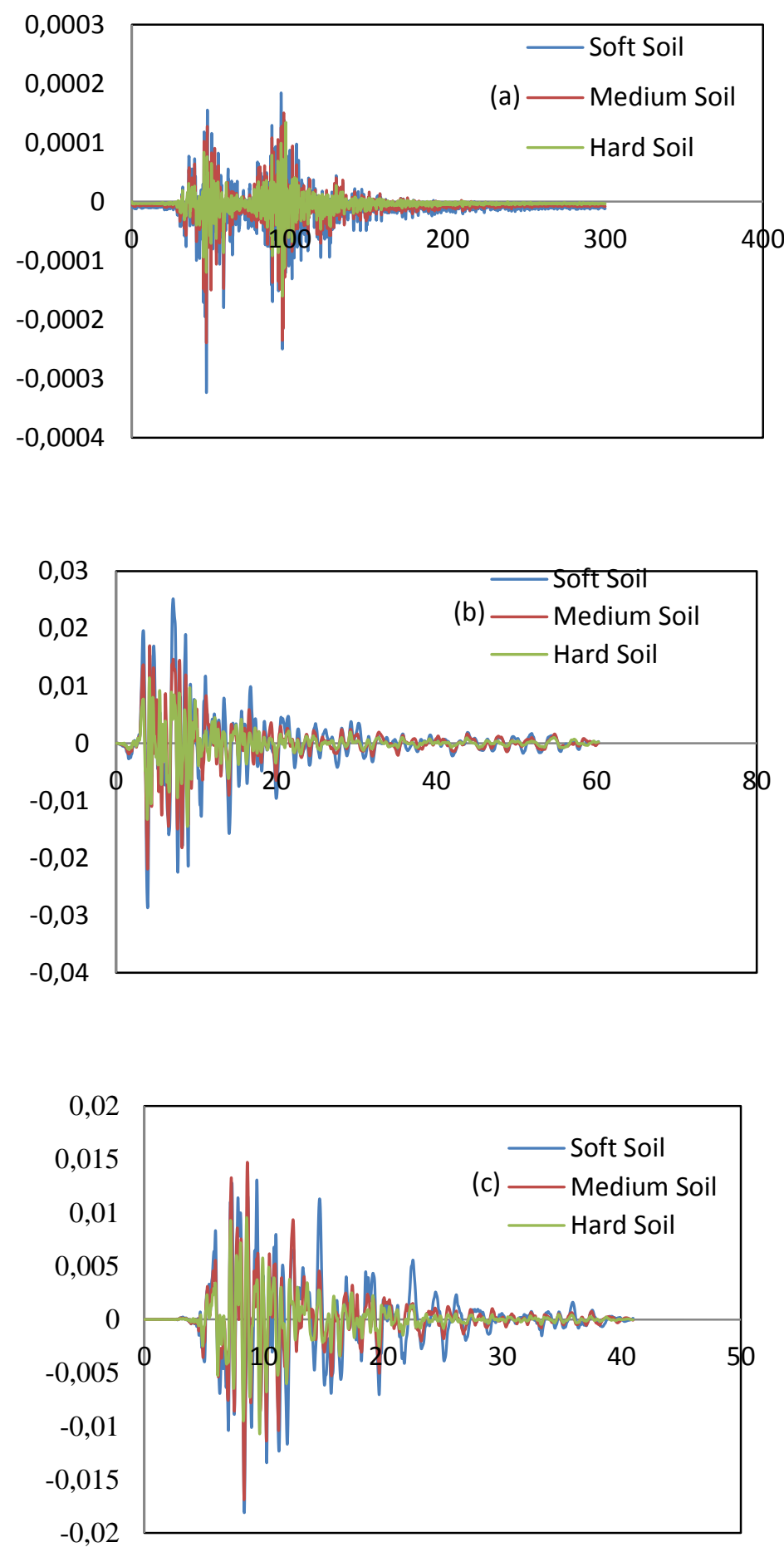
In the same way, the figure 7 shows the effect of the soil properties on the interface region that can be regrouped in:

- Maximum deflections at the interfacial medium are less than of the frame structure ones.

- Under earthquake records used, the behavior of the interaction region is so identically to those of the frame structure.

- The structural damage occurs first at the interface level before spreads to the frame structure due to its feeble characteristics.

- Seismic effects are concentrated at narrow frequency range for frame structure and interface level.

\section{Influence of the interaction ratio}

\section{Influence of the interaction factor on frame structure}

Figure 8. Influence of the interaction ratio $\xi$ on the structure response. (Self-Elaboration).
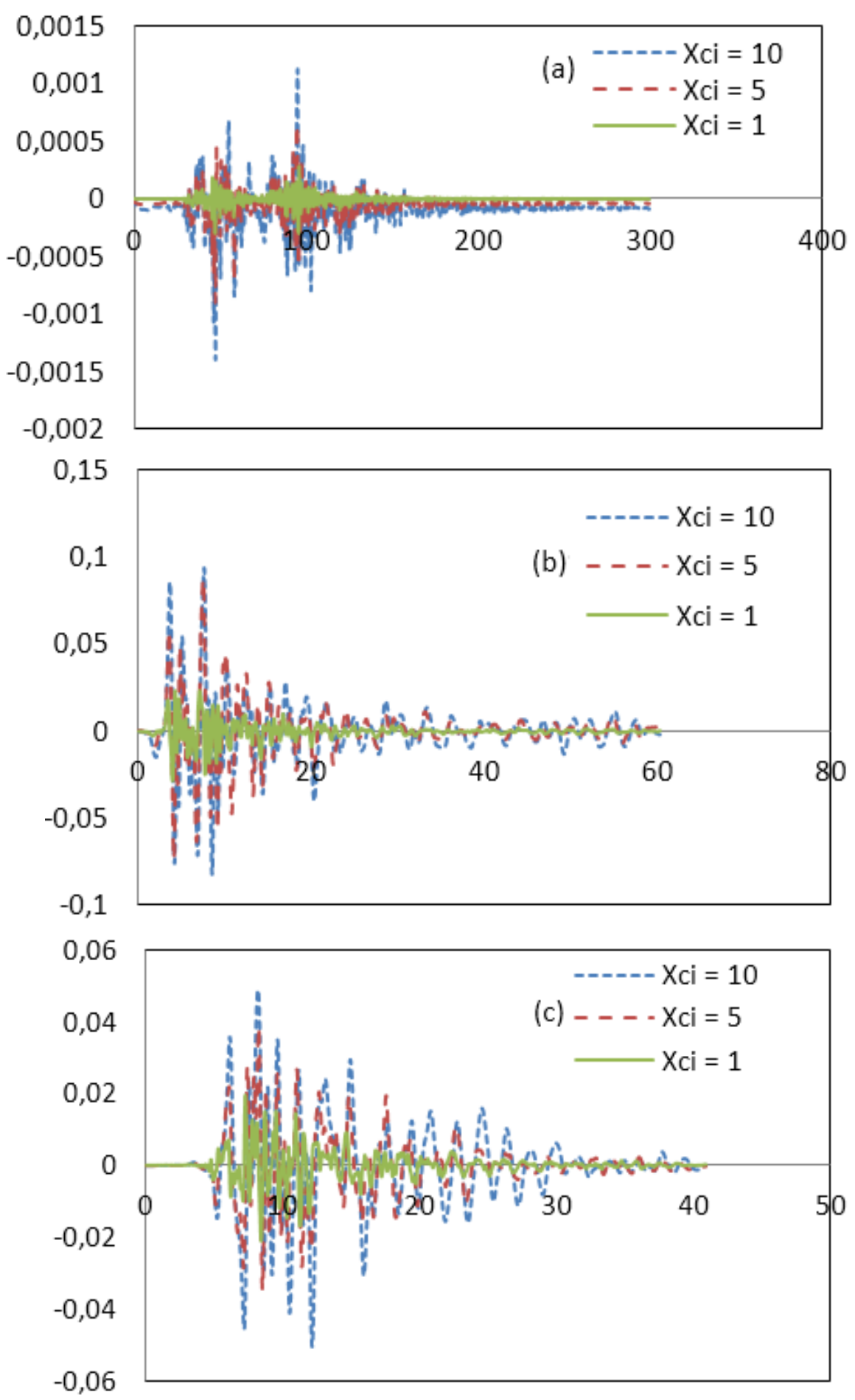

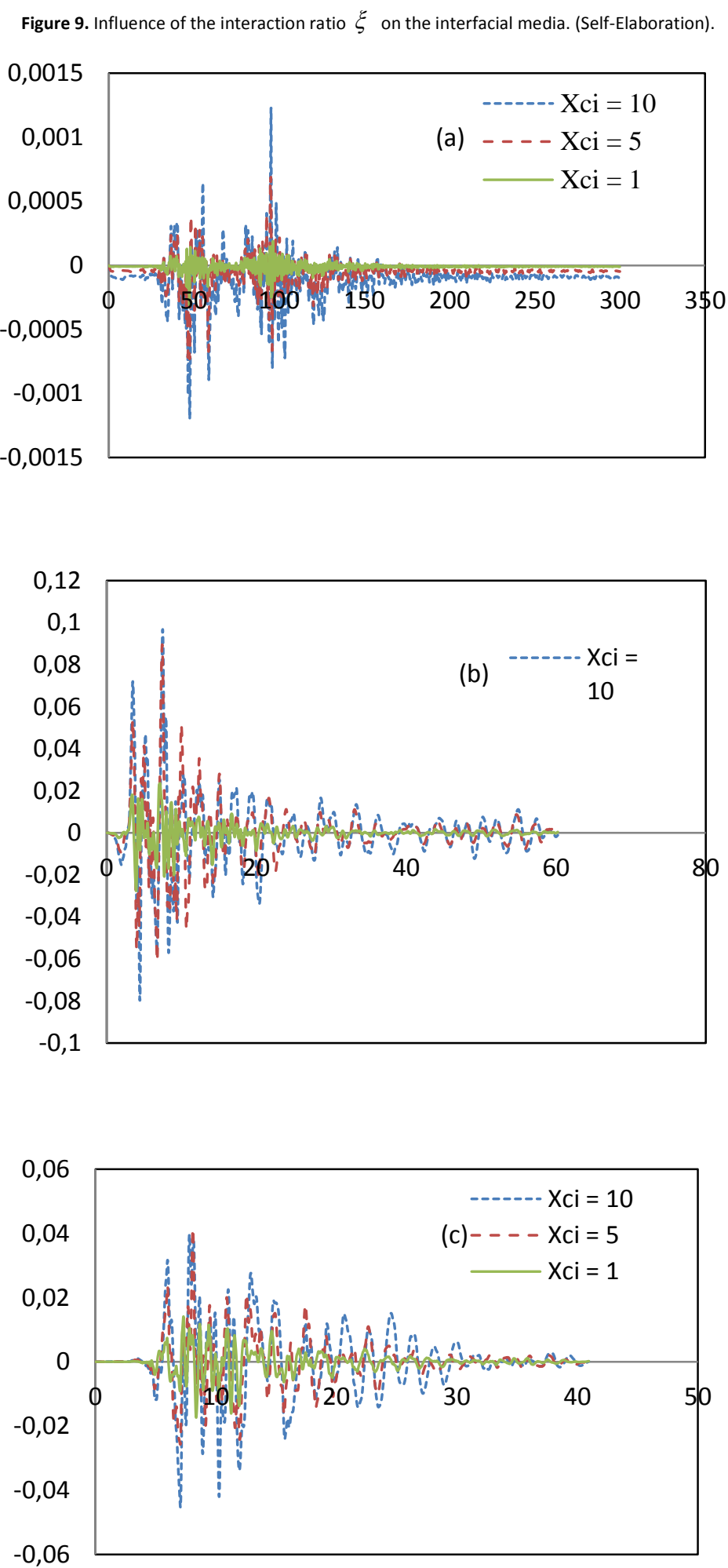

The interaction ratio affects considerably the seismic behavior of the frame structure and interaction media (Figures 89). For the selected value of the interaction ratio, the responses based deflection of the top of structure (Figure 8 ) and at the interfacial level (Figure 9) amplify with the increase of the interaction ratio. More, the interaction ratio, $\xi$, affects the frame structure and interface level at narrow frequency range. Adding, the interaction ratio has an important influence on frame structure than on the interaction media for hard soils, it's about $11.5 \%$ higher but it has an effect on the interface medium than frame structure when soft or medium soils are used, it's estimated to $6.70 \%$ higher. 


\section{Shear stresses}

The shear stresses produced at the SSI level considering Northridge earthquake have been shown in the Figure 10. This graph shows the time history of the shear stresses for different configurations of soil foundation measured at the Bnode. It has seen that the heterogeneity of layers affects considerably the behavior of the interface in term of shear stresses. In this region, shear stresses are important with the configuration C3 composed of $10 \mathrm{~m}$ (soft soil), $20 \mathrm{~m}$ (medium soil) and 50m (hard soil) compared to the configuration $\mathrm{C} 2$ constituted of $10 \mathrm{~m}$ (soft soil) accompanied with a layer of $70 \mathrm{~m}$ (medium soil) and the unique layer of $80 \mathrm{~m}$ of soft soil (configuration C1) (Figure 10).

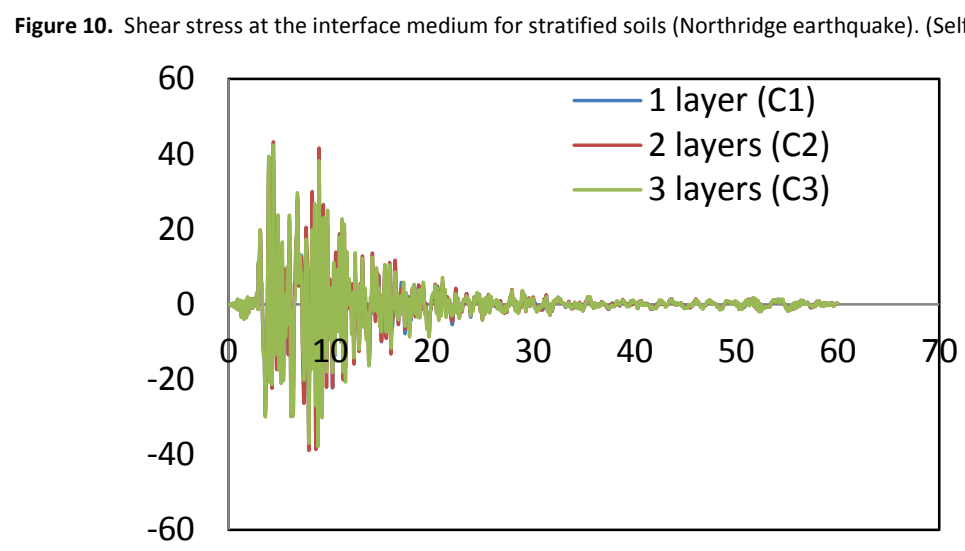

Finally, the Figure 11shows the variation of the maximum shear stresses with the depth, which decreases with the increase of the depth of the bed rock. In this case, for $z \leq 10 \mathrm{~m}$, the C1-configuration represents rigorously the behavior of the soil under the foundation but the C3-configuration reproduces the behavior of the soil foundation according for $10 \leq z \leq 30 \mathrm{~m}$. At the end, for $30 \leq z \leq 80 \mathrm{~m}$, the response of the soil foundation is well described by the $\mathrm{C} 2$ configurztion. At the bedrock level, shear stresses reproach for all configurations to a value inferior to $0.004 \mathrm{MPa}$ and become less than if the deepest of the bedrock is so considerable.

Figure 11. Pattern of shear stress with depth. (Self-Elaboration).

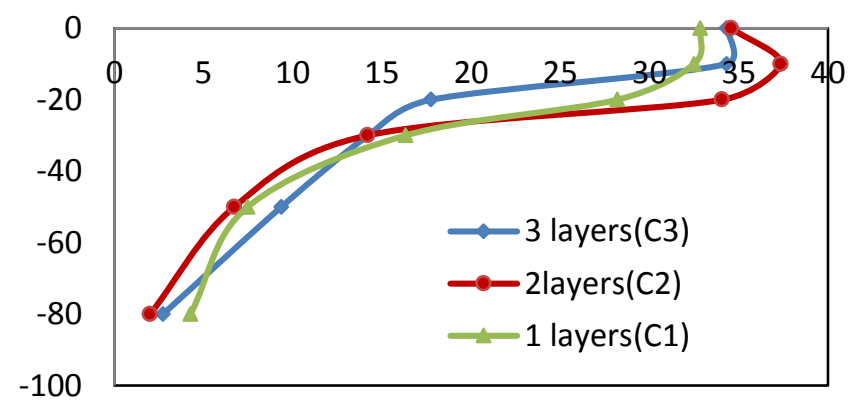

The seismic performance of frame structure including soil-structure interaction and seismic impact has been studied using the direct approach. A new thin finite element method has been introduced in the developed program to simulate the responses of the frame structure and the interface media. This numerical investigation leads to the following conclusions.

- All soil types amplify the motions at the interaction level but with different degrees. The amount of amplification is affected by many factors as: the flexibility of the soil, earthquake frequencies and the properties of interface medium.

- Buildings built on hard soils show low deflections due to the inertial and kinematic interactions compared to those on medium or soft soils.

- Seismic effects are concentrated at narrow frequency ranges and the damage caused by Tohoku earthquake is more destructive compared to Kobe and Northridge earthquakes.

- The structural damage occurs at the interface level before spreads to the framed structure. 
- Reponses based deflections of top structure and interfacial medium amplify with the increase of the interaction ratio.

- The interaction factor has an influence on frame structure than on the interaction media; it's about $11.5 \%$ and $6.70 \%$ higher for hard soils and soft or medium soils, respectively.

- The heterogeneity of layers affects considerably the behavior of the interface and maximum shear stresses decrease with the remoteness of the bed rock of the foundation.

Adhikary, S., Singh, Y., Dominik, H., Lang, D.H. \& Kumar, R. (2015). Effect of soil on seismic performance and vulnerability of RC frame buildings.Conference: Earthquake Risk and Engineering towards a Resilient World. 9-10 July 2015, Cambridge, UK.

Behnamfar, F. \& Banizadeh, M. (2016). Effects of soil-structure interaction on distribution of seismic vulnerability in RC structures. Soil Dynamics andEarthquake Engineering, 80, 73-86.

Bhojegowda, V.T. \& Subramanya, K.G. (2015). Soil structure interaction of framed structure supported on different types of foundation. International Research Journal of Engineering and Technology, 2(5), 651-660.

Boudaa, S. \& Khalfallah, S. (2019). Static Interaction Analysis between Beam and Layered soils using a Two-parameter Elastic Foundation. Int. Journal of advanced structural engineering, 11(1), 21-30.

Çelebi, E., Goktepe, F. \& Karahan, N. (2012). Non-linear finite element analysis for prediction of seismic response of buildings considering soil-structure interaction. Natural Hazards Earth System Sciences, 12,3495-3505.

Chinmayi, H.K. \& Jayalekshmi, B.R. (2016). Dynamic soil-structure interaction analysis of RC framed building with various positions of shear walls, International Journal of Earth Sciences and Engineering, 9(6), 1960-1965.

EN 1998-1 (2004). Eurocode 8: Design of structures for earthquake resistance - Part 1: General rules, seismic actions and rules for buildings, European Committee for Standardization, Brussels.

Elwi, M., Bassman Muhammed, B. \& Alhussiny, N. (2018). Evaluation of soil-structure interaction for structures subjected to earthquake loading with different types of foundation. The 3rd International Conference on Buildings, Construction and Environmental Engineering. MATEC Web of Conferences 162, 04026.

Espinoza, G., Benedetti, F., Mendoza, P. A., \& Bonilla E. (2018). Influence of the seismic excitation frequencies content on the behavior of a tuned mass damper in low-rise building considering soil-structure interaction. Latin American Journal of Solids and Structures, 15, 1-23.

Farouk, H. \& Farouk, L. (2016). Soil, Foundation, and superstructure interaction for plane two-bay frames. ASCE: Int. J. Geomech., 16(1), 1-11.

Ferro, A.N. (2013). Nonlinear dynamic soil-structure interaction in earthquake engineering. Ph.D. thesis, Ecole Centrale de Paris, France, 139 p.

Fu, C. (2015). An effective substructure analysis for soil-structure interaction.5th International Conference on Civil Engineering and Transportation. Atlantis press: $175-178$

Gazetas, G. (2015). 4th Ishihara lecture: soil-foundation-structure systems beyond conventional seismic failure thresholds. Soil Dyn. Earthquake Eng., 68, 23-39.

Guerdouh, D. \& Khalfallah, S. (2019). Effects and behaviour of soil-frame structure interaction under dynamic loading, Under review. Građevinar, 71(9).

Greer, A. (2012). Earthquake Preparedness and Response: Comparison of the United States and Japan. Leadership Management and Engineering, 12(3), 111-125.

Hashamdar, H., Ibrahim,M. \& Jameel M. (2011). Finite element analysis of nonlinear structures with Newmark method. International Journal of the Physical Sciences, 6(6), 1395-1403.

Hokmabadi, A.S. (2014). Effect of dynamic Soil-pile-structure Interaction on seismic response of mid-rise moment resisting frames. Ph. D. thesis, University of Sydney, Australia, $220 \mathrm{p}$.

Ismail, A. (2014). Effect of soil flexibility on seismic performance of 3-D frames. Journal of Mechanical and Civil Engineering, 11(4), $135-143$.

Liratzakis, A. \& Tsompanakis, Y. (2018). Impact of soil saturation level on the dynamic response of masonry buildings. Frontier in Built Environment, 4, $\mathrm{N}^{\circ} 24$.

Lysmer, J. \& Kuhlemeyer, R.L. (1969). Finite dynamic model for infinite media. J. Eng. Mech. Div., 95, 859-877.

Martinez-Rodrigo, M.D., Galvin, P., Doménech A. \& Romero, A. (2018). Effect of soil properties on the dynamic response of simply-supported bridges under railway traffic through coupled boundary element-finite element analyses. Engineering Structures, 70, 78-90.

Mayer, M.H. \& Gaul, L. (2007). Segment-to-segment contact elements for modeling joint interfaces in finite element analysis, Mechanical systems and signal processing, 21(2), 724-734.

Medina, C., Aznárez, J.J., Padrón, L.A. \& Maeso, O. (2013). Effects of soil-structure interaction on the dynamic properties and seismic response of piled structures. Soil Dynamics and Earthquake Engineering, 53,160-175. 
Millen, M.D.L., Pampanin, S., Cubrinovski, M. \& Carr, A. (2014). A design framework for soil-foundation-structure interaction. Proceedings of 2nd European Conference in Earthquake Engineering and Seismology. Istanbul, Turkey.

Mylonakis, G., Nikolaou, S. \& Gazetas, G. (2006). Footings under seismic loading: analysis and design issues with emphasis on bridge foundations.Soil Dyn. Earthq.Eng., 26, 824-853.

Nibhorkar, S.S. (2017). Effect of Soil Structure Interaction on structure: A Review. Journal of Geotechnical Studies, 2(3), 1-5.

NIED (2018). Earthquakes. National Research Institute for Earth and Disaster Resilience. Japan. Retrieved from http://www.bosai.go.jp/e/activities/database/earthquake.html

Penava, D., Kraus, I., Petronijević, M. \& Schmid, G. (2018). Dynamic soil-structure analysis of tower-like structures using spectral elements. Technical Gazette,25(3), 738-747.

Pecker, A., Paolucci, R., Chatzigogos, C., Correia, A.A. \& Figini, R. (2014). The role of non-linear dynamic soil-foundation interaction on the seismic response of structures. Bull. Earthquake Eng., 12, 1157-1176.

Tabatabaiefar, H.R., Samali, B. \& Fatahi, B. (2010). Effects of dynamic soil-structure interaction on inelastic behavior of mid-rise moment resisting buildings on soft soils. Australian Earthquake Engineering Society Conference. Perth, Western Australia.

Teodoru, I.B. (2009). Beams on elastic foundation, the simplified continuum approach, Buletinul Institutului Politehnic, 4, 37-45.

Thusoo, R., Modi, K., Kumar R. \& Madahar, H. (2015). Response of buildings with soil-structure interaction with varying soil types. International Journal of Civil andEnvironmental Engineering, 9(4), 414-418.

Tomeo, R., Bilotta, A., Pitilakis, D. \& Nigro, E. 2017. Soil-structure interaction effects on the seismic performances of reinforced concrete moment resisting frames. Procedia Engineering, 199, 230-235.

Ramancharla, P.K. (2015). Importance of dynamic soil-structure interaction analysis in design of tall buildings and infrastructure. International Symposium on Reducing Earthquake Losses and Advances in Earthquake Science. Gujarat, India.

Shoaei, M., Huat, B., Jaafar, M.,\& Alkarni A. (2015). Soil-framed structure interaction analysis -a new interface element. Latin American Journal of Solids and Structures, 12, 226-249.

Zafarkhah, E. \& Dehkordi, M.R. (2017).Evaluation and numerical simulation of soil type effects on seismic soil-structure interaction response of RC structures. Journal of Vibroengineering, 19(7), 5208-5230.

Zienkiewicz, O.C. \& Taylor, R. (1991). The finite element method. $4^{\text {th }}$ Edition, 1-2, McGraw-Hill, London.

Zienkiewicz, O.C.\& Bettess, P. (1976). Infinite Elements in the Study of Fluid-Structure Interaction Problems. Second International Symposium on Computing Methods in Applied Science and Eng. Versailles, France. 